\title{
Basic ammonothermal GaN growth in molybdenum capsules
}

S. Pimputkar*, J. S. Speck, S. Nakamura 


\begin{abstract}
Single crystal, bulk gallium nitride $(\mathrm{GaN})$ crystals were grown using the basic ammonothermal method in a high purity growth environment created using a non-hermetically sealed molybdenum (Mo) capsule and compared to growths performed in a similarly designed silver (Ag) capsule and capsule-free René 41 autoclave. Secondary ion mass spectrometry (SIMS) analysis revealed transition metal free $\left(<1 \times 10^{17} \mathrm{~cm}^{-3}\right) \mathrm{GaN}$ crystals. Anomalously low oxygen concentrations $\left((2-6) \times 10^{18} \mathrm{~cm}^{-3}\right)$ were measured in a $\{0001\}$ seeded crystal boule grown using a Mo capsule, despite higher source material oxygen concentrations $\left((1-5) \times 10^{19}\right.$ $\mathrm{cm}^{-3}$ ) suggesting that molybdenum (or molybdenum nitrides) may act to getter oxygen under certain conditions. Total system pressure profiles from growth runs in a Mo capsule system were comparable to those without a capsule, with pressures peaking within 2 days and slowly decaying due to hydrogen diffusional losses. Measured Mo capsule GaN growth rates were comparable to un-optimized growth rates in capsule-free systems and appreciably slower than in Ag-capsule systems. Crystal quality replicated that of the GaN seed crystals for all capsule conditions, with high quality growth occurring on the (0001) Ga-face. Optical absorption and impurity concentration characterization suggests reduced concentrations of hydrogenated gallium vacancies $\left(\mathrm{V}_{\mathrm{Ga}}-\mathrm{H}_{\mathrm{x}}\right)$.
\end{abstract}




\section{Keywords:}

A1. Impurities; A2. Ammonothermal crystal growth; A2. Single crystal growth; B1. Bulk GaN; B1. Nitrides, B1. Molybdenum Nitride 


\section{Introduction}

Gallium nitride $(\mathrm{GaN})$ and related group-III alloys are wide-band gap semiconductors with applications in optoelectronic and electronic devices. Most notably, GaN and its alloys with indium have enabled blue LEDs which in turn have resulted in white solid-state lighting sources with wide-ranging, positive societal impact. ${ }^{1}$ Despite remarkable progress in this field, most of the optoelectronic and electronic devices are still grown on foreign substrates, yielding highly defective epitaxial layers. Widespread availability of high quality, large area GaN substrates of arbitrary orientation would provide tremendous opportunities for further improving device efficiencies $^{2}$ and enable vertical device structures with implications for high efficiency power electronic devices permitting operation at high voltages, frequencies, and temperatures. ${ }^{3}$

Bulk, single crystals of GaN are challenging to grow as it is nearly impossible to realize a congruent, stoichiometric liquid phase. The ammonothermal method circumvents this problem by dissolving GaN into a solution of supercritical ammonia. While its viability has been demonstrated $^{4,5,6,7}$, improvements to growth rates are desired to reduce cost of the resulting GaN substrates. ${ }^{8}$ Recent advances have shown that improved growth rates can be achieved for basic ammonothermal growth of $\mathrm{GaN}$ when performed in a silver capsule system. The capsule was a pressure balanced, closed, non-hermetically sealed container made of high purity silver providing a high purity growth environment and was placed within an unlined nickel-chromium (NiCr) superalloy autoclave body. While total growth rates of up to 344 um/day for growth in both $c$-directions was achieved (a 70\% improvement over comparable capsule-free growths ${ }^{9}$ ), an understanding of the role of the silver capsule is still outstanding. A few possible mechanisms were suggested to explain this observed behavior, including reduced decomposition of ammonia, 
catalytic behavior of silver, or reduced surface step pinning due to the significant reduction of transition metal impurities.

In the current study, it is of interest to explore what aspects of deploying a silver capsule contributed to improved growth rates. An indirect approach can be taken by developing a comparably high purity growth environment made of a material other than silver. Additionally, it is of interest to explore alternative materials suitable for high temperature and long-term exposure to basic ammonothermal given the observed softening and deformation of silver parts in excess of $600{ }^{\circ} \mathrm{C}$. Cobalt alloys and molybdenum materials are potentially stable and robust materials. $^{10}$

This paper will explore the suitability of using pure molybdenum for a capsule system for creating a high purity, basic ammonothermal GaN growth environment. Silver was deliberately added to certain growth runs to determine any impact on growth. The design and dimensions of the parts making the pure molybdenum capsule system are comparable to those making the previously reported pure silver capsule system permitting comparisons between the two growths. ${ }^{9}$ Growth results from the pure molybdenum capsule ('Mo capsule') system will be compared to reported results from GaN growth in capsule-free, René 41 autoclaves ('No capsule', 'capsule-free') and autoclaves containing a pure silver capsule ('Ag capsule').

\section{Experimental Methods}

Basic ammonothermal growth of $\mathrm{GaN}$ was performed in $\mathrm{NiCr}$ superalloy (René 41) autoclaves with an inner diameter of $25 \mathrm{~mm}$ and an inner length of $280 \mathrm{~mm}$. A pure molybdenum capsule $(99.95 \%)$ was introduced into the inner volume such that the capsule formed an internal volume which was non-hermetically sealed from the internal René 41 autoclave walls. The 
capsule itself as well as internal components used to contain the GaN source material, suspend the GaN seed crystals, and separate the source and growth zones were fabricated to be identical in design and dimension to that of the design reported in Ref [9] using silver, though were made out of pure molybdenum $(99.95 \%)$ for this study.

Five different growth runs under varying growth conditions were performed using GaN seed crystals (Mitsubishi Chemical Company, MCC) fabricated from $+c$-plane GaN boules grown using hydride vapor phase epitaxy (HVPE). A variety of $\sim 330 \mu \mathrm{m}$ thick seed crystals were with large, primary exposed $\{0001\},\{11 \overline{2} 0\},\{10 \overline{1} 0\}$, or $\{11 \overline{2} 2\}$ surfaces were derived from the $\mathrm{GaN}$ boules and polished on both sides. A hole was drilled through each crystal to permit suspension within the growth zone using a thin wire attached to a stand.

The same polycrystalline GaN source material $(1-2.8 \mathrm{~mm}$ in size, $\sim 30 \mathrm{~g})$ was used for each growth run, with $~<5 \%$ added from the same stock as makeup between each run.

Sodium was used as the sole mineralizer material. Residual oxide and oil originating from the storage container was removed by paring external surfaces of the sodium cubes in a nitrogen-filled glove box $\left(\mathrm{O}_{2}\right.$ and $\left.\mathrm{H}_{2} \mathrm{O}<1 \mathrm{ppm}\right)$. Purified ammonia was condensed into the sealed autoclave following addition of sodium, source, seeds, and capsule system.

To determine the chemical stability of the molybdenum parts, all parts were inspected and weighed before and after each growth run. For all but one growth run, silver was deliberately added to the growth system by replacing the molybdenum basket holding the GaN source material and the molybdenum wires used to suspend the crystals from the stand with pure silver (>99.99\%) analogies. For one of the growth runs, a $25 \mathrm{~mm}$ long, $5 \mathrm{~mm}$ diameter solid rod of titanium-zirconium-molybdenum alloy (TZM) rod was added to the bottom of the growth zone. 
Additional details of the growth system, equipment and operating procedures used to handle, fill, operate, open, and clean the autoclaves can be found in Ref [9]. Identical procedures were followed with the exceptions of capsule material (molybdenum or silver) along with specific growth details provided in Table 1.

Table 1. Performed growth runs with values on source and seed temperatures, growth duration, sodium and ammonia fill and metals present within the molybdenum capsule

\begin{tabular}{|c|c|c|c|c|c|c|c|}
\hline \multirow{2}{*}{ Run } & \multicolumn{2}{|c|}{$\begin{array}{c}\text { External Wall } \\
\text { Temperature }\left({ }^{\circ} \mathrm{C}\right)\end{array}$} & \multirow{2}{*}{$\begin{array}{c}\text { Growth } \\
\text { Duration } \\
\text { (days) }\end{array}$} & \multicolumn{2}{|c|}{ Fill (mol/l) } & \multirow{2}{*}{$\begin{array}{l}\text { Capsule } \\
\text { Material }\end{array}$} & \multirow{2}{*}{$\begin{array}{l}\text { Additional } \\
\text { Metals inside } \\
\text { Capsule }\end{array}$} \\
\hline & $\mathrm{T}_{\text {source }}$ & $\mathrm{T}_{\text {growth }}$ & & $\mathrm{Na}$ & $\mathrm{NH}_{3}$ & & \\
\hline$\# 1$ & 515 & 565 & 8 & 1.332 & 22.65 & Mo & \\
\hline$\# 2$ & 550 & 600 & 4.3 & 1.273 & 20.12 & Mo & $\mathrm{Ag}, \mathrm{TZM}$ \\
\hline \#3 & 515 & 560 & 7.7 & 2.559 & 21.99 & Mo & $\mathrm{Ag}$ \\
\hline$\# 4$ & 515 & 575 & 10.4 & 2.638 & 22.05 & Mo & $\mathrm{Ag}$ \\
\hline$\# 5$ & 535 & 575 & 60 & 1.311 & 22.48 & Mo & $\mathrm{Ag}$ \\
\hline
\end{tabular}

The resulting grown crystals were characterized for structural quality using omega X-ray rocking curves $(\omega$-XRC) measured using X-ray diffraction (XRD, Philips PANalytical MRD Pro 3D) with a $\mathrm{Cu} \mathrm{K}$ s source and a spot size of $1 \mathrm{~mm}$ x $10 \mathrm{~mm}$. Growth thicknesses were measured using a micrometer (Mitutoyo, $\pm 1 \mu \mathrm{m}$ ). Impurity concentrations were determined using secondary ion mass spectrometry (SIMS, Cameca IMS 7F) for four crystals, one each from 
growth runs \#2-\#5, on the as-grown surface. Optical reflection and transmission properties were determined at room temperature using a UV-vis-NIR spectrophotometer (Agilent Cary $500)$.

The effectiveness of the capsule towards preventing introduction of impurities originating from the autoclave wall was verified post-run by confirming the lack of incorporation of $\mathrm{Mn}$ (an impurity sourced solely from $\mathrm{NiCr}$ superalloy autoclave components) into the grown crystal using SIMS ([Mn] D.L. of $\sim 1 \times 10^{17} \mathrm{~cm}^{-3}$ ). For GaN growth in capsule-free systems, a concentration of low to mid $10^{18} \mathrm{~cm}^{-3}$ is typically observed.

Powder was harvested from molybdenum materials post-run by submerging the parts in deionized water and sonication for 15 minutes. The resulting black powder containing suspension was passed through a $0.5 \mu \mathrm{m}$ paper filter and dried in a vacuum oven. The powder was compacted and characterized using powder XRD (Philips PANalytical XPERT Powder). The weights of the crystals and molybdenum parts before and after growth were measured using a balance (Mettler Toledo, $\pm 0.01 \mathrm{mg}$ ). Energy-dispersive X-ray spectroscopy (EDX, Oxford INCA X-ray system) was performed on molybdenum and TZM parts post-run after removing surface contamination with a soft wipe and sonication in de-ionized water and isopropanol for 15 minutes.

\section{Results and Discussion}

\subsection{Growth System Behavior}

The purity of the growth environment can be inferred from impurities incorporated into the bulk GaN crystal during growth assuming no significant difference in impurity uptake between growth in capsule-free, Ag-, or Mo-capsule systems. With this assumption, SIMS 
analysis suggested that the Mo capsule was as successful as the Ag capsule in providing a pure growth environment, as concentrations for transition metals were similar: $[\mathrm{Mn}]<1 \times 10^{17} \mathrm{~cm}^{-3}$ and $[\mathrm{Fe}]<2 \times 10^{16} \mathrm{~cm}^{-3}$. No molybdenum was detected in any of the four analyzed crystal boules (detection limit: $\sim 1 \times 10^{17} \mathrm{~cm}^{-3}$ ). Incorporation of non-transition metal impurities varied depending on growth direction, though comparably so to Ag capsule runs, resulting in impurity ranges of $[\mathrm{C}] \sim(2-6) \times 10^{17} \mathrm{~cm}^{-3},[\mathrm{Si}] \sim(3-30) \times 10^{17} \mathrm{~cm}^{-3}$, and $[\mathrm{Mg}]<1 \times 10^{17} \mathrm{~cm}^{-3}$. Hydrogen was measured at an order of magnitude lower concentration, $[\mathrm{H}] \sim 9 \times 10^{18} \mathrm{~cm}^{-3}$, when compared to typical values in the low to mid $10^{20} \mathrm{~cm}^{-3}$ for growth in both capsule-free and Ag-capsule systems. Sodium was found in all crystals, $[\mathrm{Na}] \sim(3-300) \times 10^{16} \mathrm{~cm}^{-3}$, and is comparable to crystals grown in capsule-free or Ag-capsule systems.

Oxygen concentrations in two opposing growth zones parallel to the initial seed crystal orientation for the four different crystal boules analyzed are shown in Figure 1. The oxygen incorporation tracks previously observed behavior in $\mathrm{GaN}$ grown in $\mathrm{Ag}$ capsules, though at overall slightly lower concentrations. It is significant to note that the $c$-plane oriented boule from run \#5 had substantially lower oxygen concentrations than the source material. Oxygen concentrations appreciably below $1 \times 10^{19} \mathrm{~cm}^{-3}$ have not been measured in crystals grown in a capsule-free or Ag-capsule system suggesting molybdenum may act as an oxygen getter under certain conditions. A complete mass spectrum of the same crystal revealed no other additional impurities. 


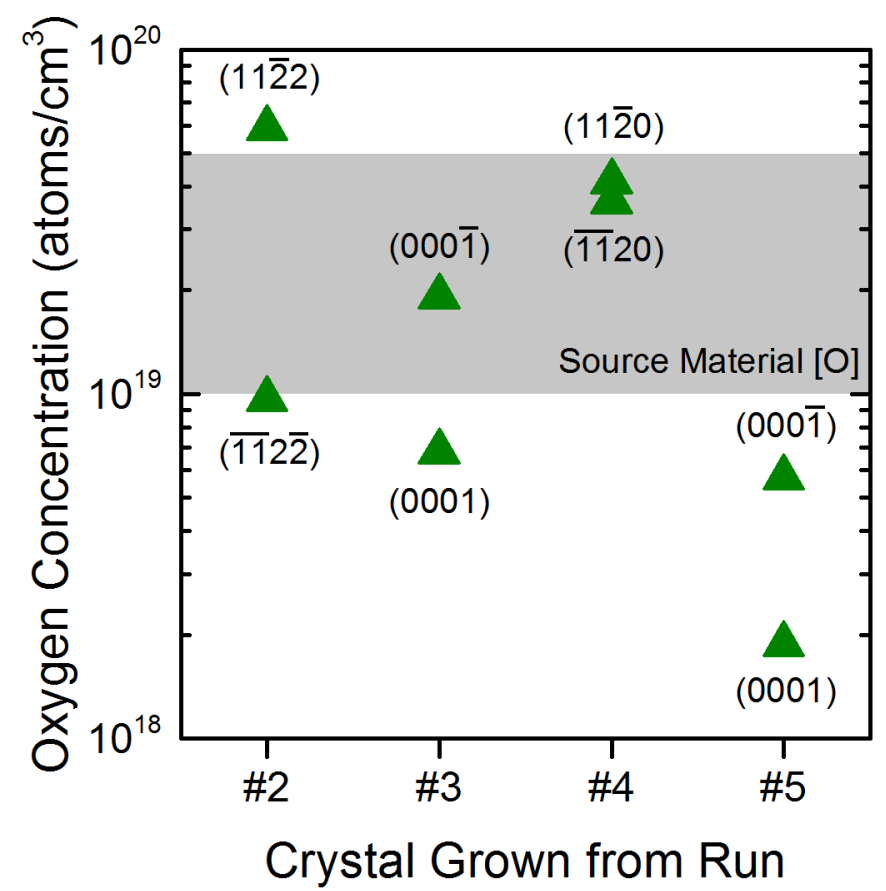

Figure 1. Oxygen impurity levels in grown GaN crystal determined using secondary ion mass spectrometry (SIMS) for crystal grown on the indicated surface of the seed crystal during the specified growth run (see Table 1 for details). Grey shaded area indicates range of typical oxygen impurity levels measured in polycrystalline GaN source material.

Typical total system pressure traces for all three capsule systems are shown in Figure 2 and a differing total system pressure behavior can be observed between Mo- and Ag-capsule systems despite comparable high purity growth environments. The pressure traces for the Mocapsule and capsule-free system displayed a rapid pressure rise, presumably due to decomposition of ammonia into hydrogen and nitrogen resulting in an overall increase in molar concentration of gases in the system, followed by a slow decay. The peak pressure in Mo capsules were consistently reached a day earlier than the capsule-free system (2 days vs. 3 days), suggesting the presence of Mo enhances ammonia decomposition rates. The slow decay in total 
system pressure as a function of growth time for the Mo-capsule and capsule-free systems can be explained by diffusional losses of hydrogen out of the system, since both $\mathrm{Mo}$ and $\mathrm{NiCr}$ superalloy materials have large and similar hydrogen permeabilities. ${ }^{11,12,13}$ The lack of pressure decay in the Ag-capsule system can be explained by silver's appreciably lower hydrogen permeability. ${ }^{14}$

Even though all three systems experienced different ammonia decomposition rates, the peak pressures (before hydrogen diffusion losses for Mo-capsule and capsule-free systems) were the same to within the accuracy of the pressure transducers $(\sim 6 \mathrm{MPa})$. This suggests the degree or extent of ammonia decomposition was similar for the Mo- and Ag-capsule systems given comparable fill for $\mathrm{NH}_{3}$ and $\mathrm{Na}$, though different for the capsule-free system which was filled with $10 \%$ less $\mathrm{NH}_{3}$ and $\mathrm{Na}$. A total system pressure difference of $\sim 23 \mathrm{MPa}$ would have been anticipated given modeling of the growth system assuming a pure $\mathrm{NH}_{3}$ fill and permitting thermodynamic equilibrium to be reached for the two different fill densities of $\mathrm{NH}_{3}(22 \mathrm{~mol} / \mathrm{l}$ for the Mo and $\mathrm{Ag}$ capsule and $20 \mathrm{~mol} / \mathrm{l}$ for the capsule-free system). ${ }^{15}$

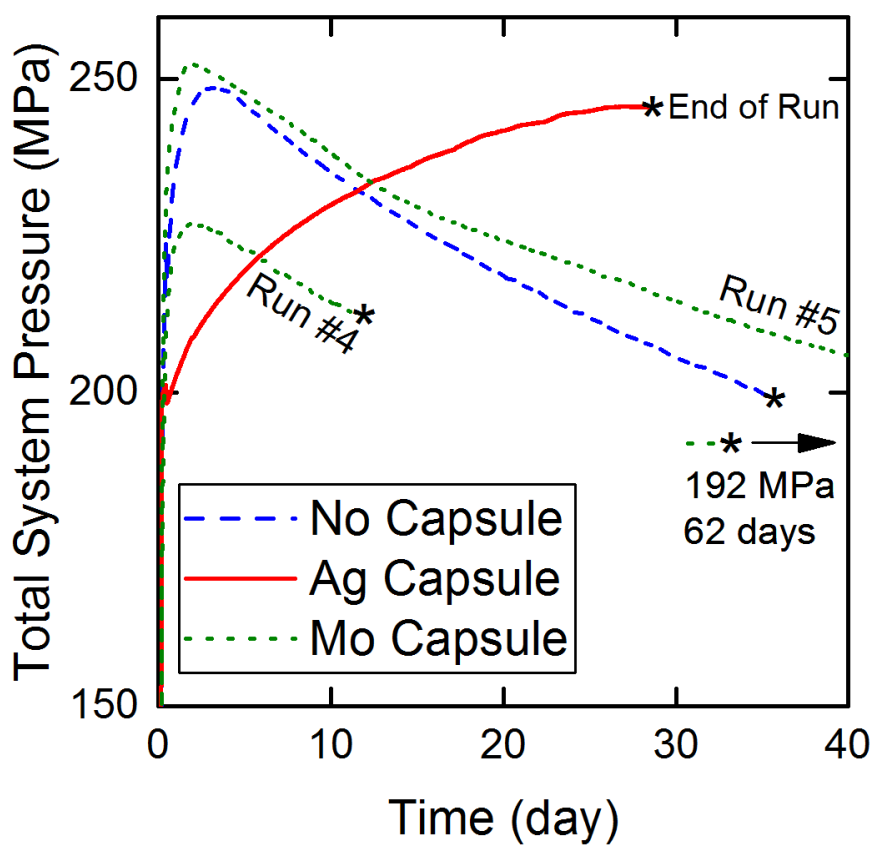


Figure 2. Total system pressure traces for GaN growth runs performed in René 41 autoclaves without a capsule (Ref [9]), with a silver capsule (Ref [9]), or with a molybdenum capsule (Run \#4 and \#5, see Table 1 for details)

\subsection{GaN Growth}

The measured growth rates in the Mo capsule are considerably lower than those in the Ag capsule, as shown in Fig 3, and comparable to those for un-optimized growths in capsule-free systems. The surface morphologies were similar to growths performed in capsule-free or Agcapsule systems. The persistently slow growth rate in the $m$-direction suggests an intrinsic, crystallographic limitation towards enhanced growth rates.

Three possible explanations can be put forth to explain the reduced growth rates assuming no additional impurities are present in the system other than those already observed in Ag-capsule or capsule-free systems. As the Mo-capsule system was not as optimized for growth as the Ag-capsule systems, it is possible that differing thermal conductivity of molybdenum $(\sim 140 \mathrm{~W} / \mathrm{mK}$ at room temperature $)$ vs. silver $(\sim 400 \mathrm{~W} / \mathrm{mK}$ at room temperature $)$ resulted in reduced mass transport due to changes in established fluid motion. Nevertheless, enhanced growth rates in Ag capsules occurred under comparable external wall temperature for the capsule-free systems and it is therefore deemed unlikely that the addition of a material with a thermal conductivity smaller than that of silver though still an order of magnitude greater than that of NiCr superalloys would have such a substantial detrimental impact on established fluid motion and hence mass transport.

A second possible explanation for reduced growth rates in the Mo capsule system may be 
the introduction of a large Ga sink due to the many possible Mo-Ga intermetallic phases. However, XRD of powder harvested post-run from Mo capsule components did not indicate the presence of any Ga containing compounds. Additionally, no evidence of Ga was found using EDX analysis of a molybdenum baffle plate present in the capsule during growth for more than 90 days and a TZM rod present in the growth zone for 5 days. These results suggest that Ga uptake by the Mo capsule was negligible, and therefore cannot explain the reduced growth rates.

A third explanation for reduced growth rates in Mo-capsule and capsule-free systems is the enrichment of $\mathrm{N}_{2}$ and concurrent reduction in $\mathrm{NH}_{3}$ concentration due driven by the diffusional loss of hydrogen during growth. Since the driving force for growth, and thus growth rate, should be strongly linked to the relative activities of $\mathrm{NH}_{3}, \mathrm{~N}_{2}$ and $\mathrm{H}_{2}$, changing this equilibrium should impact the growth rate. In fact, increased growth rates in our previous reports involving the use of a silver capsule were speculated to be attributed to this effect. These results motivate a dedicated study on the impact of changes in activities of $\mathrm{NH}_{3}, \mathrm{~N}_{2}$ and $\mathrm{H}_{2}$ on the resulting growth rates.

After low growth rates were found in Run \#1, a silver basket and silver seed crystal suspension wires were used in later runs to observe any catalytic effect on growth rate or pressure behavior. However, no impact on growth rate or pressure behavior was evident. For certain runs, polycrystalline GaN grew on the walls in the growth zone, so the solution must have been highly supersaturated. Since the growth environment chemistries are assumed to be largely similar between the Ag capsule and Ag-containing Mo capsule conditions, any catalytic effect of silver should have been similar, whether acting as a free surface or a dissolved species. As this was not the case, it is likely that the observed enhanced growth rates in Ag-capsule systems are not due to any catalytic behavior of the Ag towards growth. 


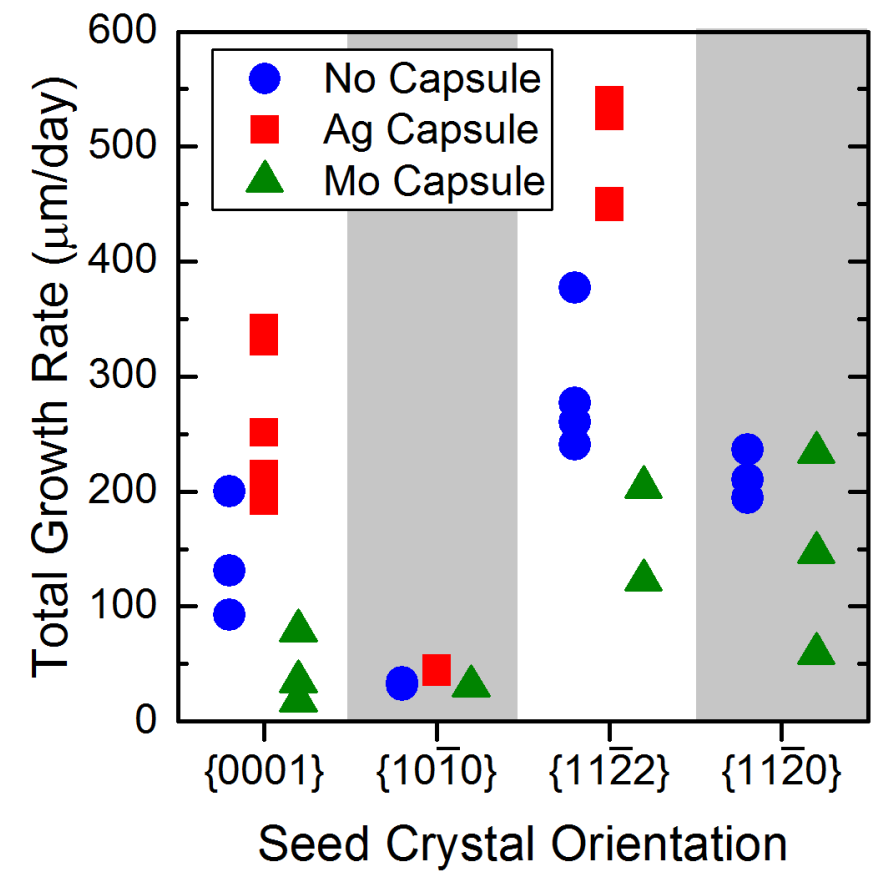

Figure 3. Summary of combined total growth rates along directions normal to indicated seed crystal orientation for systems without a capsule (Ref [9]), with a silver capsule (Ref [9]), or with a molybdenum capsule (this work)

Crystals grown in Mo capsules replicated the quality of the seed crystal as characterized by two perpendicular on-axis and one off-axis $\omega$-XRC scans. Figure 4 summarizes $\omega$-XRC traces for two crystals shown in Figure 5, while Table 2 summarizes their FWHM values. No cracking was observed in these crystals. The rocking curve FWHM values were comparable to those of the seed crystal and the presence of minor mis-oriented columnar grains in the seed crystal were replicated in the grown crystal (see Figure 4 a) and b)). 
Growth on the Ga-face of $c$-plane oriented seeds typically results in a deterioration of crystal quality in capsule-free or Ag-capsule systems, but was not observed for any crystal grown using a Mo capsule. While this may have been a consequence of slower growth rates, deterioration in crystal quality was observed for crystals grown at comparable growth rates in capsule-free systems.
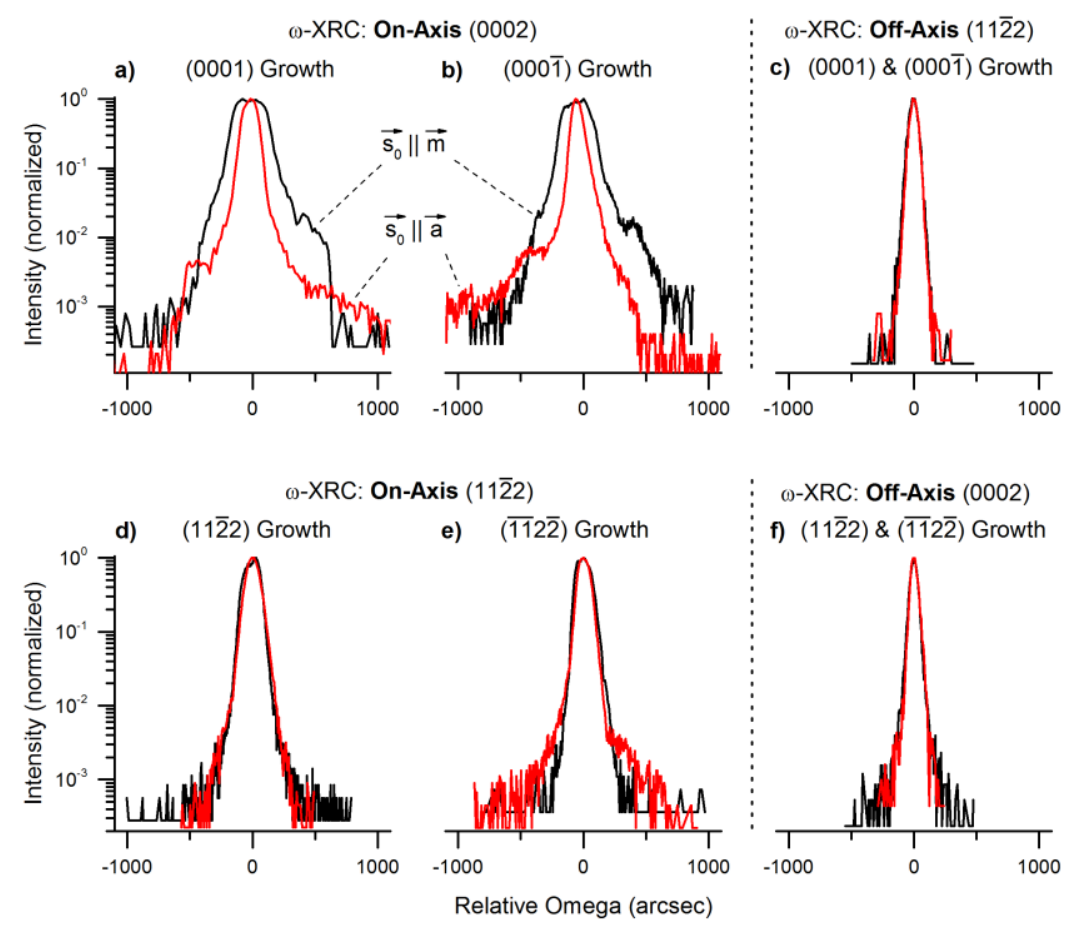

Figure 4. Omega X-ray rocking curves ( $\omega$-XRC) for crystals shown in Figure 5: (0001) boule a) - c) and $(11 \overline{2} 2$ ) boule $d)$ - f) for which two on-axis scans were performed for each side of the boule with an incident X-ray beam $\left(\overrightarrow{s_{0}}\right)$ direction parallel to either the $\vec{m}$ (black trace) or $\vec{a}$ (red trace) (a), b), (0002) Bragg planes) and $\vec{c}$ (black trace) or $\vec{m}$ (red trace) (d), e), (112 2$)$ Bragg planes) directions. Off-axis scans are provided for c) (112̄2) Bragg planes (red trace: (0001) 
growth, black trace: $(000 \overline{1})$ growth) and f) (0002) Bragg planes (red trace: $(11 \overline{2} 2)$ growth, black trace: $(\overline{11} 2 \overline{2})$ growth). See Table 2 for FWHM values and crystal growth thicknesses.

Table 2. On-axis and off-axis omega X-ray rocking curve ( $\omega$-XRC) full width at half maximum (FWHM) for crystals shown in Figure 5 and traces provided in Figure 4. X-ray spot size was 1 $\mathrm{mm} \times 10 \mathrm{~mm}$.

\begin{tabular}{cccc}
\hline \multirow{2}{*}{$\begin{array}{c}\text { Seed } \\
\text { Orientation }\end{array}$} & Growth Zone & \multicolumn{2}{c}{ FWHM of $\omega$-XRC $(\operatorname{arcsec})$} \\
\cline { 3 - 4 } & & On-Axis & Off-Axis \\
\hline \multirow{2}{*}{0001} & $(0001)$ & $140-296$ & 84 \\
& $(000 \overline{1})$ & $91-251$ & 78 \\
\hline \multirow{2}{*}{$1 \overline{2} 2$} & $(11 \overline{2} 2)$ & $117-150$ & 66 \\
& $(\overline{11} 2 \overline{2})$ & $112-142$ & 59 \\
\hline
\end{tabular}

Crystals grown in Mo capsules were transparent and consistently exhibited a grey coloration under ambient room light (see Figure 5), without any orange/yellow coloration typically seen for comparably transparent crystals grown in Ag capsules. Sub-band gap optical reflection and transmission experiments revealed qualitatively comparable behavior between crystals grown in $\mathrm{Ag}$ and Mo capsules, with pronounced absorption above $\sim 3.0 \mathrm{eV}$. For GaN grown in Ag-capsule systems, hydrogenated gallium vacancies $\left(\mathrm{V}_{\mathrm{Ga}}-\mathrm{H}_{\mathrm{x}}\right)$ were identified to be the 
probable origin of this defect absorption. ${ }^{16}$ Based on this and the observed reduction in hydrogen concentrations in these crystals, $\mathrm{V}_{\mathrm{Ga}}-\mathrm{H}_{\mathrm{x}}$ complexes for $\mathrm{GaN}$ grown in Mo-capsule systems are likely present but at reduced concentrations compared with GaN grown in Ag-capsule systems.

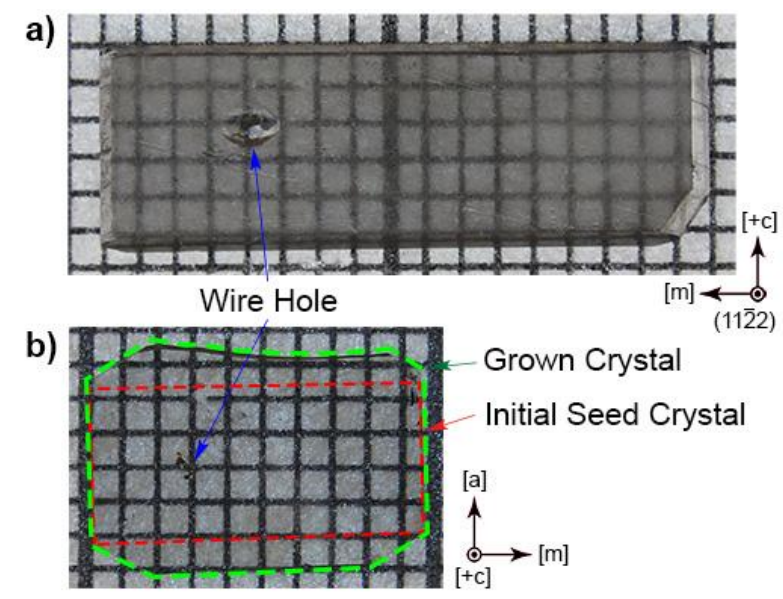

Figure 5. Transmitted light images of post-growth, as-grown crystal boules for a) (11 $\overline{2} 2)$ and b) (0001) oriented seed crystal. Total thickness of boule along a) [11 $\overline{2} 2] 840 \mu \mathrm{m}$ and b) [0001] 622 $\mu \mathrm{m}$ with embedded seed crystal with thickness of $310 \mu \mathrm{m}$ or $355 \mu \mathrm{m}$, respectively.

\subsection{Stability of Molybdenum}

Post-run all molybdenum parts exposed to elevated temperatures in the growth zone $\left(\mathrm{T}_{\text {external wall }}>560^{\circ} \mathrm{C}\right.$ ) exhibited both darkened surfaces and were covered with loosely adhered black powder. Neither of these behaviors were observed for molybdenum parts in the colder source zone $\left(\mathrm{T}_{\text {external wall }}<550{ }^{\circ} \mathrm{C}\right)$ of the autoclave. A TZM sample placed in the growth zone had a similar dark surface, though did not shed as much black powder. Cumulative weight changes for all molybdenum parts post-run and removal of loosely adhered black powder 
normalized by growth time indicated continuous molybdenum loss occurred at a rate of $\sim 10-25$ mg/day (see Figure 6). Powder XRD of the black powder post-run for run \#4 is shown in Figure 7 and suggests it is primarily composed of hexagonal $\delta$-MoN (Powder Diffraction File (PDF) card 98-006-0168) with lesser amounts of cubic $\mathrm{Mo}_{3} \mathrm{~N}_{2}$ (PDF card 01-089-3712).

These results suggest that pure molybdenum may not be a suitable material for use at elevated temperatures under basic ammonothermal conditions, due to the lack of formation of a protective adherent nitride coating. A TZM test piece, experienced a $\sim 4 \mathrm{x}$ smaller area-specific mass loss, so TZM may be better suited for use under these conditions. Despite the formation of molybdenum nitride under basic ammonothermal conditions, it may not form as readily under acidic ammonothermal conditions based on literature reports. ${ }^{10,17,18}$

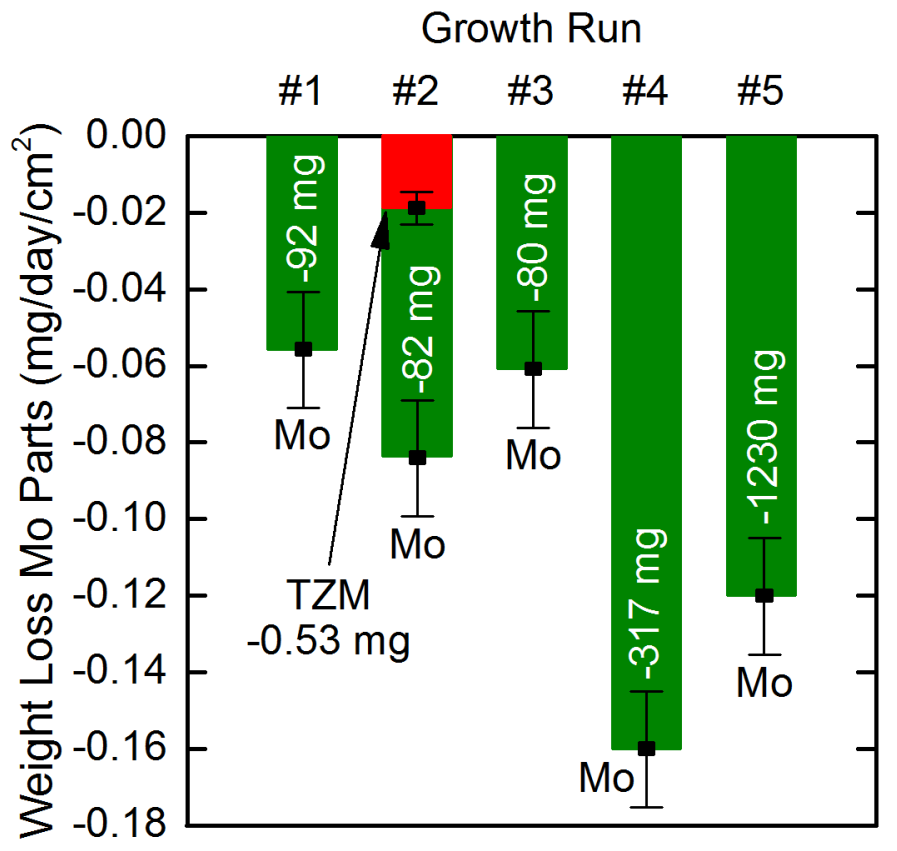

Figure 6. Area normalized weight change of pure molybdenum (Mo) and titanium-zirconiummolybdenum (TZM) materials exposed to growth environment for specified growth run (see 
Table 1 for details) after removal of loosely adhered black powder on the surface. Total weight loss of Mo or TZM parts is provided for each run.

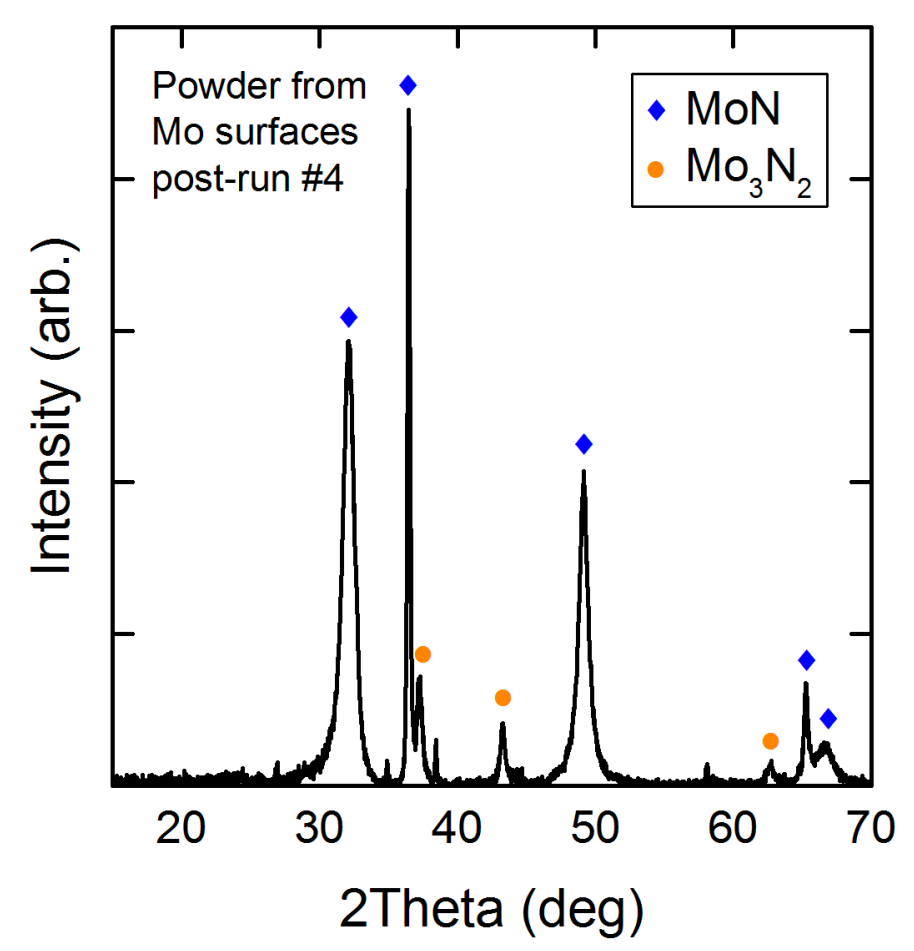

Figure 7. Powder X-ray diffraction (XRD) pattern of the loosely adhered black powder removed from the surfaces of the pure molybdenum parts after growth run \#4. Indicated peaks correspond to anticipated peak positions for MoN (PDF card 98-006-0168) and $\mathrm{Mo}_{3} \mathrm{~N}_{2}$ (PDF card 01-0893712). Remaining peaks could not be identified.

\section{Summary}

GaN was successfully grown in a Mo capsule using the basic ammonothermal method 
and sodium as the mineralizer. Growth results were compared to growths in a similar Ag capsule system and in a system without a capsule. ${ }^{9}$

SIMS analysis revealed that impurity concentrations in the grown crystal boules were comparable to those grown in Ag capsule systems, suggesting the Mo capsule was as successful as the Ag capsule in removing impurities originating from the autoclave walls. Anomalously low oxygen concentrations $\left((2-6) \times 10^{18} \mathrm{~cm}^{-3}\right)$ were measured in a $\{0001\}$ seeded crystal boule, despite the source material containing higher oxygen concentrations $\left((1-5) \times 10^{19} \mathrm{~cm}^{-3}\right)$ suggesting molybdenum may act as an oxygen getter under certain conditions.

The total system pressure profile of the Mo capsule behaved comparably to systems without a capsule, characterized by rapidly reaching peak pressures within $\sim 2$ days for Mo capsule or $\sim 3$ days for capsule-free systems followed by a continuous, slow decay of the pressure due to hydrogen diffusion. The peak pressure values for given temperatures and fill densities of $\mathrm{NH}_{3}$ and $\mathrm{Na}$ were comparable to Ag-capsule systems and lower by $\sim 10 \%$ when compared to anticipated values based on capsule-free systems. The permeability of hydrogen though molybdenum is higher than that through silver suggesting despite comparable high purity growth environments the chemical composition of the solvent in the Mo capsule system gradually shifts to a solution with increased $\mathrm{N}_{2}$ and reduced $\mathrm{NH}_{3}$ concentrations.

Growth rates in the Mo capsule were comparable to non-optimized growths in capsulefree systems and lower than Ag-capsule systems, despite the deliberate addition of silver to the system, suggesting silver may not be chemically or catalytically active in these growth systems. The GaN crystals grown in the Mo-capsule systems replicate the crystal quality of the seed and high quality growth on the Ga-face of $c$-plane oriented seeds was observed which has not been commonly observed in Ag or capsule-free systems. The grown GaN crystals were transparent 
with a grey darkening and lacking any significant orange/yellow coloration which is observed in GaN crystals grown in $\mathrm{Ag}$ or capsule-free systems. Optical reflection and transmission measurements suggest the presence of hydrogenated gallium vacancies, though an order of magnitude lower hydrogen concentrations in the GaN crystals, as compared to Ag-capsule and capsule-free GaN, suggest a reduction in their concentration.

\section{Acknowledgments}

The authors wish to thank Mohammed Abo Alreesh for performing EDX measurements and Dr. Tom Mates for his assistance in performing SIMS. The authors acknowledge the support from the Solid State Lighting and Energy Electronics Center at University of California, Santa Barbara and the MRL Central Facilities, which are supported by the MRSEC Program of the NSF under Award No. DMR 1121053; a member of the NSF-funded Materials Research Facilities Network (www.mrfn.org). 


\section{References}

${ }^{1}$ J.Y. Tsao, M.H. Crawford, M.E. Coltrin, A.J. Fischer, D.D. Koleske, G.S. Subramania, G.T. Wang, J.J. Wierer, R.F. Karlicek, Toward Smart and Ultra-efficient Solid-State Lighting, Advanced Optical Materials. 2 (2014) 809-836. doi:10.1002/adom.201400131.

${ }^{2}$ C.A. Hurni, A. David, M.J. Cich, R.I. Aldaz, B. Ellis, K. Huang, A. Tyagi, R.A. DeLille, M.D. Craven, F.M. Steranka, M.R. Krames, Bulk GaN flip-chip violet light-emitting diodes with optimized efficiency for high-power operation, Appl. Phys. Lett. 106 (2015) 031101. doi:10.1063/1.4905873.

${ }^{3}$ S. Chowdhury, B.L. Swenson, M.H. Wong, U.K. Mishra, Current status and scope of gallium nitride-based vertical transistors for high-power electronics application, Semicond Sci Tech. 28 (2013) 074014. doi:10.1088/0268-1242/28/7/074014.

${ }^{4}$ R.T. Dwiliński, R.M. Doradziński, J. Garczyński, L.P. Sierzputowski, R. Kucharski, M. Zając, M. Rudziński, R. Kudrawiec, W. Strupiński, J. Misiewicz, Ammonothermal GaN substrates: Growth accomplishments and applications, Phys. Stat. Sol. (a). 208 (2011) 1489-1493. doi:10.1002/pssa.201001196.

${ }^{5}$ W. Jiang, D. Ehrentraut, J. Cook, D.S. Kamber, R.T. Pakalapati, M.P. D'Evelyn, Transparent, conductive bulk GaN by high temperature ammonothermal growth, Phys. Stat. Sol. (B). 252 (2015) 1069-1074 doi:10.1002/pssb.201451587.

${ }^{6}$ E.R. Letts, T. Hashimoto, S. Hoff, D. Key, K. Male, M. Michaels, Development of GaN wafers via the ammonothermal method, J. Cryst. Growth. 403 (2014) 3-6. doi:10.1016/j.jcrysgro.2014.06.004.

${ }^{7}$ Y. Mikawa, T. Ishinabe, S. Kawabata, T. Mochizuki, A. Kojima, Y. Kagamitani, H. Fujisawa, Ammonothermal growth of polar and non-polar bulk GaN crystal, Proc. of SPIE. 9363 (2015) 936302-936302-6. doi:10.1117/12.2078137.

${ }^{8}$ T. Fukuda, D. Ehrentraut, Prospects for the ammonothermal growth of large GaN crystal, J. Cryst. Growth. 305 (2007) 304-310. doi:10.1016/j.jcrysgro.2007.04.010. 
${ }^{9}$ S. Pimputkar, S. Kawabata, J.S. Speck, S. Nakamura, Improved growth rates and purity of basic ammonothermal GaN, J. Cryst. Growth. 403 (2014) 7-17. doi:10.1016/j.jcrysgro.2014.06.017.

${ }^{10}$ S. Pimputkar, T.F. Malkowski, S. Griffiths, A. Espenlaub, S. Suihkonen, J.S. Speck, S. Nakamura, Stability of materials in supercritical ammonia solutions, J. of Supercritical Fluids. 110 (2016) 193-229. doi:10.1016/j.supflu.2015.10.020.

11 T. Tanabe, Y. Yamanishi, S. Imoto, Hydrogen permeation and diffusion in molybdenum, Journal of Nuclear Materials. 191-194 (1992) 439-443. doi:10.1016/S0022-3115(09)80083-4.

12 Le Claire, A.D. AERE Harwell 1981, Report 9911, 1-61

${ }^{13}$ Le Claire, A.D. AERE Harwell 1983, Report 10846, 1-38

${ }^{14}$ Chou, I.-M. American Journal of Science 1986, 286, 638-658

${ }^{15}$ S. Pimputkar, S. Nakamura, Decomposition of supercritical ammonia and modeling of supercritical ammonia-nitrogen-hydrogen solutions with applicability towards ammonothermal conditions, J. of Supercritical Fluids. 107 (2016) 17-30. doi:10.1016/j.supflu.2015.07.032.

${ }^{16}$ S. Pimputkar, S. Suihkonen, M. Imade, Y. Mori, J.S. Speck, S. Nakamura, Free electron concentration dependent sub-bandgap optical absorption characterization of bulk GaN crystals, J. Cryst. Growth. 432 (2015) 49-53. doi:10.1016/j.jcrysgro.2015.09.016.

${ }^{17}$ B. Hertweck, T.G. Steigerwald, N.S.A. Alt, E. Schluecker, Applicability of Metals as Liner Materials for Ammonoacidic Crystal Growth, Chemical Engineering \& Technology. 37 (2014) 1835-1844. doi:10.1002/ceat.201400414. 
${ }^{18}$ T. F. Malkowski, S. Pimputkar, J. Speck, S. P. DenBaars, S. Nakamura, Acidic Ammonothermal Growth of Gallium Nitride in a Liner-Free Molybdenum Alloy Autoclave, J. Cryst. Growth. (2016) (submitted) 